\title{
An integrated approach for improved management of an island's scarce water resources under climate change and tourism development
}

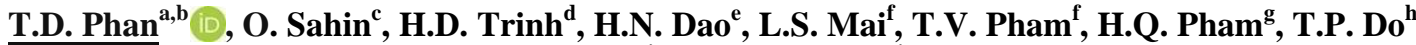 \\ T.M. Vu ${ }^{\mathrm{i}}$, and S.J. Capon \\ ${ }^{a}$ Institute of Research and Development, Duy Tan University, Da Dang, Vietnam, ${ }^{b}$ Griffith Centre for Coastal \\ Management, Gold Coast, Queensland, Australia, ${ }^{c}$ Griffith School of Engineering and Built Environment, \\ Griffith University, Gold Coast, Queensland, Australia, ${ }^{d}$ Fauna and Flora International, Hanoi, Vietnam, \\ ${ }^{e}$ Cat Ba National Park, Hai Phong, Vietnam, ${ }^{f}$ Cat Ba Langur Conservation Project, Hai Phong, Vietnam, \\ ${ }^{g}$ VNU University of Science, Hanoi, Vietnam, ${ }^{h}$ Department of Agricultural and Rural Development, Hai \\ Phong, Vietnam, ${ }^{i}$ National Economics University, Hanoi, Vietnam, ${ }^{j}$ Griffith School of Environment and \\ Science, Griffith University, Nathan, Queensland, Australia \\ Email: pduythuc@gmail.com or thuc.phan@griffith.edu.au
}

\begin{abstract}
The management of island water systems in highly developed tourism destinations of developing countries presents many challenges in the face of climate change. Such systems are high levels of uncertainty and complexity driven by dynamic interactions amongst multiple climatic and non-climatic drivers with many feedbacks. Understanding complex interactions and feedbacks in the systems is, therefore, critical to develop a long-term strategy for safeguarding a growing water demand from socio-economic development. In this study, an integrated approach was applied to improved management of scarce water resources in Cat $\mathrm{Ba}$ Island under high levels of climate change and socio-economic stressors. Specifically, a range of relevant historical data was collected and examined to identify interrelations among climatic and non-climatic drivers on the island water resources. In addition, 961 households in six communes and one town in the Cat Ba Island were interviewed to understand respondents' perspectives on threats and adaptation options for the management of the island's scarce water system. Results of relevant historical data analysis and respondents' perspectives were used together with focus group discussions to develop a causal loop diagram (CLD) for the Cat Ba Island's scarce water resource system under high levels of climate change and tourism development.
\end{abstract}

The CLD provides a comprehensive representation of the island's scarce water resources driven by multiple relationships and interactions amongst climatic and non-climatic drivers as well as adaptation options, represented by two reinforcing loops (R1 and R2), and ten balancing loops (B1 to B10). These loops provide further information on the potential water scarcity in the island in both current and future conditions. Specifically, water demand has been observed to be significantly increased over time due to high levels of population growth and tourism development, depicted by two reinforcing loops (R1 and R2). However, water supply has been decreasing over time due to sea level rise and precipitation decline. These observations are represented by ten balancing loops (B1 to B10) in which seven balancing loops (B4 to B10) represent a "Drifting goals" system archetype to seek the stability in water availability in the system.

The next stage of this study is to apply a system dynamics model (SDM) to assess the vulnerability of the island water system in 47 years, from 2014 to 2050 under climatic and non-climatic changes. Simulations targets the year 2050 because it provides a long-term perspective from which the long-term dynamic behaviour of the island water system and the consequences of the plausible future scenarios could be assessed to inform adaptation decision-making. The key climatic and non-climatic drivers and adaptation options from the CLD will be incorporated into the SDM to assess the vulnerability of the island water system and effectiveness of adaptation options under climate change and socio-economic stressors over time. The SDM will be calibrated using relevant historical data, and validated by local stakeholders for decision-making supports. A contingent evaluation method is also applied to examine the determinant factors influencing respondents' willingness to pay (WTP) for building reservoirs and increasing water price for improved management of scarce water resources in a highly developed tourism island under climate change. The logistic regression models and Bayesian networks will be used to identify determinants of the respondents' WTP for the management of the island's scarce water system. The results of this study will assist decisionmakers and water managers to understand dynamics behaviour of the system over time, and respondents' perceptions, thereby applying more effective practices to the management of scarce water resources under high levels of climate change and tourism development in the Cat $\mathrm{Ba}$ Island, Vietnam.

Keywords: Community perceptions, climate change, socio-economic stressors, island scarce water resources, systems thinking approach 


\section{INTRODUCTION}

Decision makers face many challenges in the management of island water systems in highly developed tourism destinations. The water supply sources of these islands mainly depend on drilled and dug wells, reservoirs and household rainwater tanks which are strongly driven by changes and interactions in local precipitation, temperature and sea level. These changes coupled with high rates of population growth, urbanization and tourism development have the potential to cause severe water scarcity in these islands, particularly in the developing countries. The interactions and relationships among these climatic and nonclimatic drivers create dynamic and complex processes within the systems. Systemically understanding how these drivers and interactions link together, and characterise their dynamic interactions within the systems is, therefore, needed to develop better strategies for improved management of scarce water resources under high levels of climate change and socio-economic development.

A dynamic involvement of multiple dimensional and level stakeholders in water resource management is necessary to understand their different perspectives on the resource that they are using for their daily activities. These perceptions are one of the essential steps in planning water conservation programs, especially assisting decision-makers to develop efficient policies for water resource management (Halkos \& Matsiori, 2016). In addition to these perspectives, collecting and analysing relevant historical data to understand relationships between the dependent components of water resource systems are the principles, assisting decision-makers to deeply understand the interactions among variables in the system, and provide further insights into systems behaviours, which are necessary to create lasting interventions for prolonged problems (Maani \& Cavana, 2007). This is a domain of the systems thinking approach, which has been proven to be a powerful tool to understand the complexity and change of any system (Sterman, 2000), such as water resource systems. Causal loop diagrams (CLDs) are powerful tools and techniques of systems thinking approach (Maani \& Cavana, 2007). The CLDs describe the influences of variables in systems where a positive (s) or negative (o) sign shows whether the variables move in the same or opposite direction. The feedback loops may occur either in reinforcing (R) or balancing (B) loops. Reinforcing loops represent growing or declining actions in the system, whereas balancing loops are self-correcting mechanisms that counteract, and oppose change (Sterman, 2000).

Systems thinking approach has been applied in many fields, for example, climate change adaptation (Richards et al., 2013), sustainable development (Nguyen \& Bosch, 2013), tourism management (Mai \& Smith, 2015) and wildlife conservation (Phan et al., 2016). However, the application of systems thinking in the management of water resources under climate change and socio-economic stressors has been rarely applied, especially the management of an island's scarce water resources in highly developed tourism destinations in developing countries. In this study, an integrated approach was applied to improve the management of the Cat Ba Island's scarce water resources under high levels of climate change and socioeconomic development. Specifically, 961 households in six communes and one town in the Cat Ba Island were interviewed to understand respondents' perspectives on the management of the island water system. These respondents' perspectives were used together with relevant historical data and focus group discussions to develop a CLD for the Cat Ba Island's scarce water resource system under high levels of climate change and tourism development. These results could assist decision makers to develop better strategies for water resource management adapting to climate changes and tourism development in the Cat Ba Island, Vietnam.

\section{METHODS}

\subsection{Questionnaire design and survey method}

The semi-structured questionnaire was predesigned and was then revised by twelve local stakeholders (e.g. decision-makers, water managers, water users and climate change experts) from Hai Phong city and Cat Ba Island through focus group discussions. During these discussions, we carefully developed the structure and proposed management fees as bids for the questionnaire that is appropriate with local conditions and usable for collecting data. The questionnaire was piloted to interview eleven households in Viet Hai commune to see whether these questions were understood and accepted by respondents, and only minor changes were made to the questionnaire as a result. The final questionnaire consisted of five sections: (1) contained information on the aim of the study and interview, and potential water shortage driven by climatic and non-climatic changes, (2) obtained information on socio-demographic characteristics of households, (3) obtained information on water resource status and water use sources, (4) obtained information on the effects of climate change and socio-economic development on water resources, and (5) explored the households' willingness to pay for the management of the island's water scarce resources under high levels of climate change and socio-economic development. The final questionnaire were used to interview 961 households (including hotels and restaurants) in six communes and one town in the Cat Ba Island to understand respondents' perspectives on 
the management of scarce water resources in the island. The total number of interviewing households was identified using as Equation 1.

where $n$ is a sample size, $N$ is a total number of households in the island and e is desired margin of errors.

There were 18,789 people corresponding to 4,902 households in 2018 (HPSO, 2019) located in Cat Ba town and six communes in the Cat Ba Island. With a designed margin error of 3\%, a $20 \%$ of the total households in each commune and town was planned to be sampled in the survey. Finally, a total number of 961 respondents were randomly interviewed by face-to-face from 9 March to 15 May 2019.

\subsection{Historical data collection and causal loop diagram development}

A range of historical datasets were collected and linear regression models were applied to identify interrelations among climatic drivers (e.g. sea level, precipitation) and non-climatic drivers (population growth, tourism development) on the Cat Ba Island's scarce water resource system. A causal loop diagram (CLD) was then built by combining historical data, ideas from focus group discussions and perceptions from 961 households in the Cat Ba Island.

\section{CASE STUDY - CAT BA ISLAND}

The case study for improved management of scarce water resources is the Cat $\mathrm{Ba}$ Island in Haiphong city in northern Vietnam (Figure 1). The Cat Ba Island is the largest of the Cat $\mathrm{Ba}$ Archipelago which has been recognised as a world biosphere reserve by UNESCO since 2004 as it has a large degree of diversity of landscape and ecosystems with more than forty white sandy beaches integrated with natural forests and rocky cliffs. The Cat Ba Island is mostly covered by tropical rain and limestone forests and has six communes and one town situating around the island with a population of 18,789 people in 2018 (CHDS, 2019).

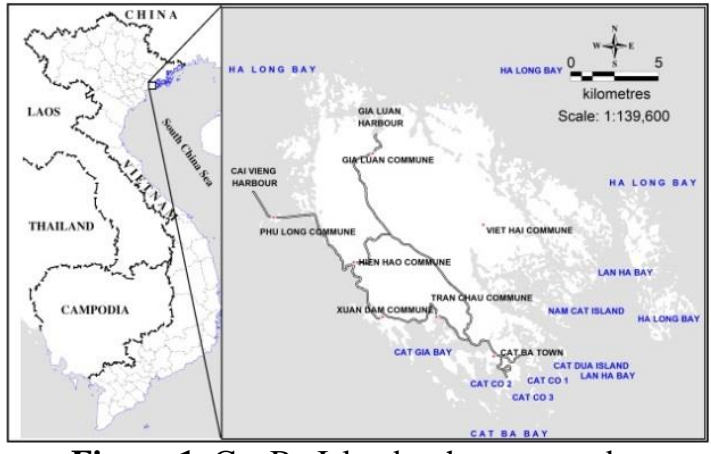

Figure 1. Cat $\mathrm{Ba}$ Island - the case study

\subsection{Community perceptions on scarce water resource management}

The respondents identified eleven threats driving the water shortage in the Cat Ba Island (Table 1). Climate change (e.g. precipitation decline, temperature increase, sea level rise) was the most dominant concerns of the respondents, followed by tourism development, population growth and water pollution. The respondents also indicated that reservoirs and their capacities have not been built sufficiently in the island to collect rainwater from raining seasons for dry seasons. Leaking water in tubes and low supply capacity of the Cat Hai Water supply plant were also identified as a driver leading to the insufficient water supply for the island's socio-economic development. In addition, the respondents mentioned that salinity intrusion in almost drilled wells, especially in the dry seasons was another driver, leading to decreased amounts of groundwater exploitation from drilled wells. Limited water supply sources were also identified by respondents because $\mathrm{Cat} \mathrm{Ba}$ is an island and its supply sources mainly depend on dug and drilled wells, and some small streams (e.g. Goi, Thuong Luong) which could supply water for reservoirs in the island. It was also noticeable that 28 respondents indicated that there were no any threats to the island water system.

Table 1. Threats to the management of the Cat Ba Island's scarce water system $(n=961)$

\begin{tabular}{|lr|lr|}
\hline Threats & Responses & Threats & Responses \\
\hline Climate change & 574 & Limited water supply sources & 71 \\
Tourism development & 555 & Over exploitation & 57 \\
Population growth & 208 & Water management concerns & 51 \\
Water pollution & 156 & Water using awareness & 25 \\
Insufficient reservoirs and their capacities & 98 & None threats & 28 \\
Water supply plant concerns & 92 & No opinion & 5 \\
Salinity intrusion & 74 & & \\
\hline
\end{tabular}


Twelve adaptation options for the management of the island's scarce water resources were suggested by the respondents in the Cat Ba Island (Table 2). Building reservoirs and increasing their storage capacities were mostly suggested by respondents, followed by using water efficient technologies, especially in hotels and restaurants, installing household rainwater tanks to collect rainwater, increasing awareness on using water, and increasing water plant capacity. In addition, building desalination plants and transported water from mainland were other options for increasing water supply capacity in the island. However, there were ten respondents who did not suggest any adaptation options for the management of the island water resources.

Table 2. Adaptation options for the management of the island's scarce water system $(n=961)$

\begin{tabular}{|ll|lr|}
\hline Adaptation options & Suggestions & Adaptation options & Suggestions \\
\hline Building reservoirs & 355 & Building desalination plants & 42 \\
Water efficient technologies & 339 & Treatment and reuse waste water & 40 \\
Installing household water tanks & 218 & Transported water from mainland & 36 \\
Increasing awareness on using water & 215 & Avoid leaking water in tubes & 24 \\
Increasing water plant capacity & 113 & Increase water price & 6 \\
$\begin{array}{l}\text { Protect the environment and plant } \\
\text { more trees }\end{array}$ & 78 & No suggestions & 10 \\
$\begin{array}{l}\text { Research groundwater sources for } \\
\text { building more drilled wells }\end{array}$ & 44 & & \\
\hline
\end{tabular}

\subsection{Causal loop diagram}

The causal loop diagram (CLD) provides a comprehensive representation of the drivers of the Cat Ba Island's scarce water resources. The CLD (Figure 2) shows that the water system in the island is influenced by temporal and spatial changes in water supply and demand over time, which is captured by two reinforcing loops (R1 and R2) and ten balancing loops (B1 to B10). The interactions between these R and B loops within the island water system over time not only produce the desired effects but also produce serious unintended consequences in the system, due to long term delays and hidden cause-effect relationships (Maani \& Cavana, 2007), thereby making the system become more dynamic and highly complex under climate change and socio-economic development.

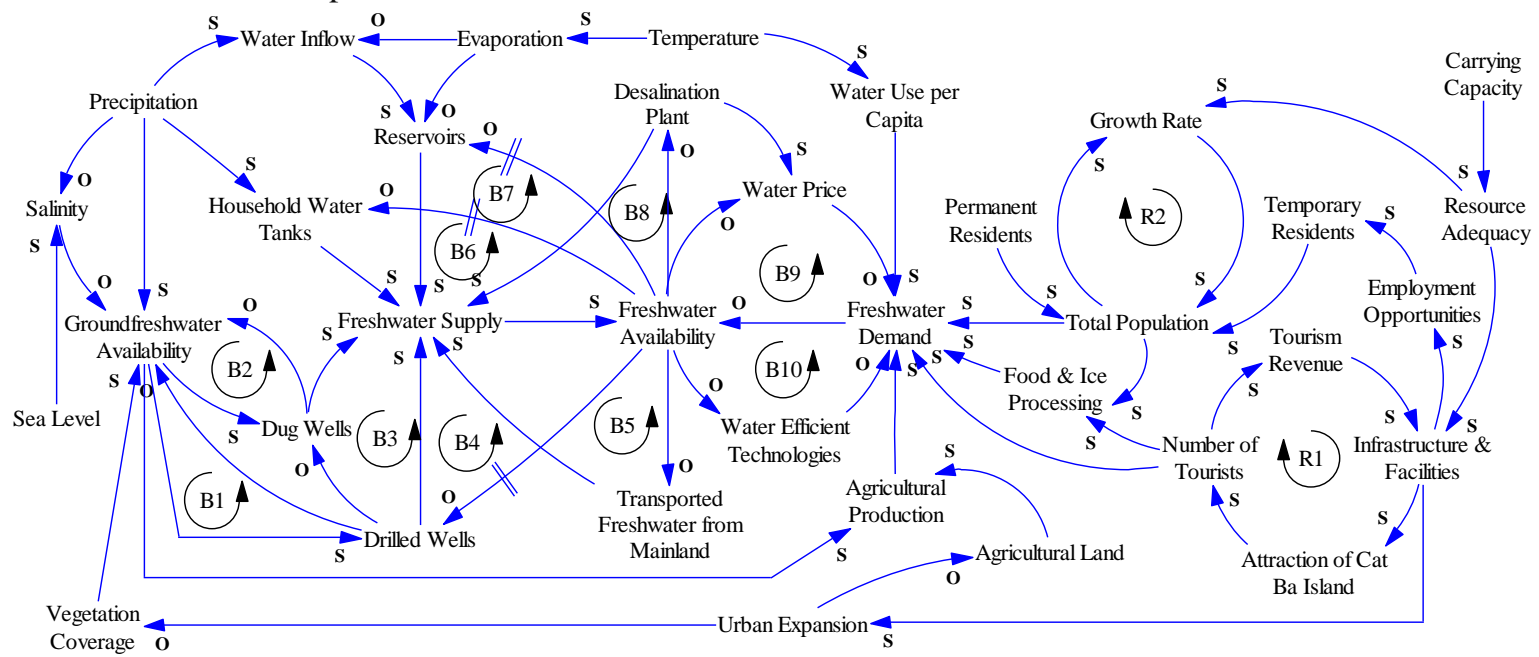

Figure 2. A causal loop diagram for an island freshwater system

$S$ : same direction; $O$ : opposite direction; $R$ : reinforce; $B$ : balance; $\neq$ : delay

The Cat $\mathrm{Ba}$ Island is considered to be one of the most beautiful places in Vietnam. It has become a preferred destination for tourists from all parts of Vietnam as well as from around the world (Mai \& Smith, 2015). As a result, the number of tourists to the island has increased significantly over the last decades (Figure 3), leading to construction of a high number of facilities, such as hotels and restaurants in the island (Figure 4). In addition, there has been a rapid increase (1\% per year) in the size of island's population due to the high birth rate and influx of migrants (Figure 5). The population growth and tourism development are two main driving forces for water consumption and drive increases in the water demand through time. These relationships are indicative of exponential growth of two reinforcing loops, R1 and R2 (Figure 2). 


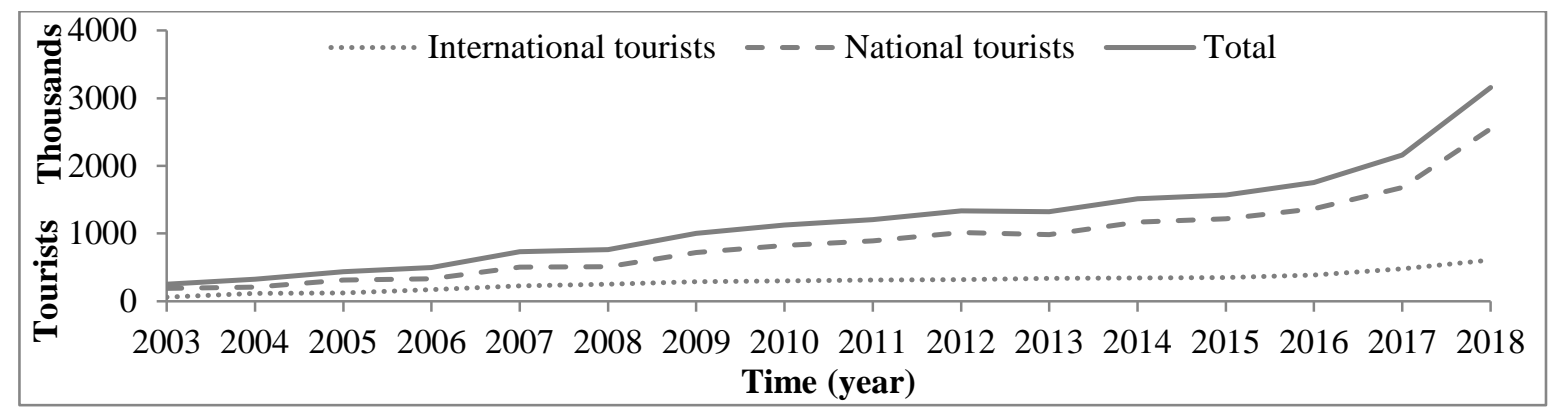

Figure 3. Tourists coming to the Cat Ba Island over a 16 year period, from 2003 to 2018 (CHDS, 2019)

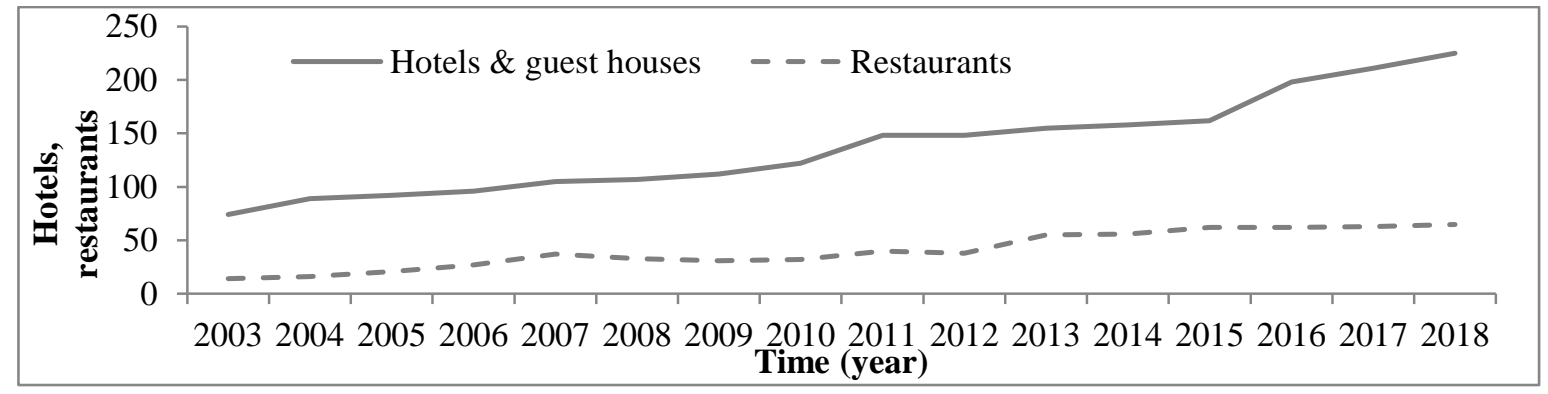

Figure 4. Hotels and restaurants in the Cat Ba Island over a 16 year period, from 2003 to 2018 (CHDS, 2019)

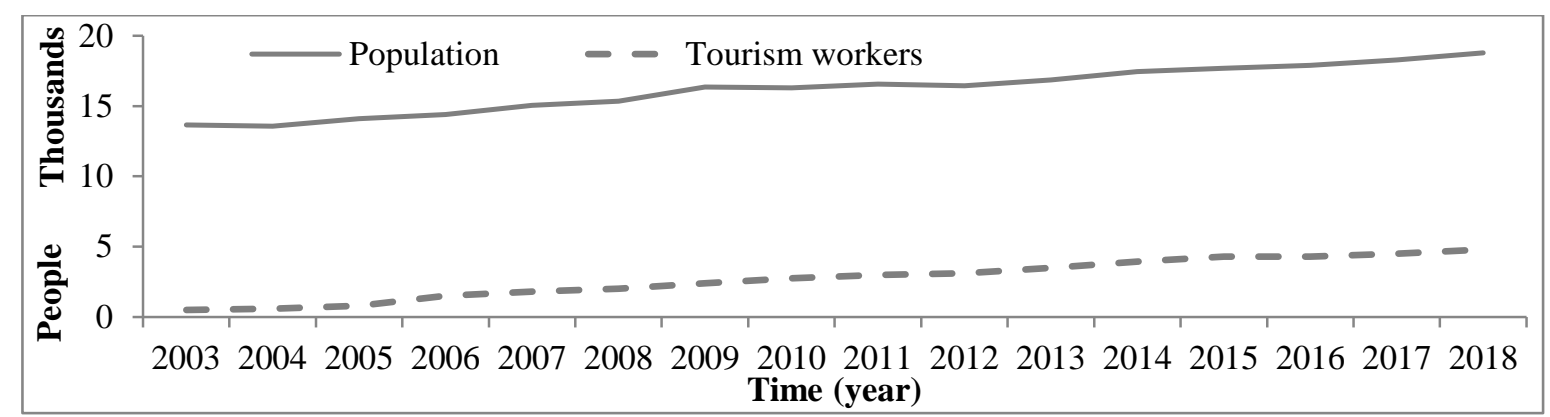

Figure 5. Population and tourism workers in the Cat Ba Island over a 16 year period, from 2003 to 2018 (CHDS, 2019)

However, the island faces many challenges in water resource management. Specifically, water supply sources of the Cat Ba Island mainly depend on drilled and dug wells, reservoirs and household rainwater tanks which are strongly driven by changes in local precipitation, temperature and sea level, and their combined effects. Over 61 years, from 1958 to 2018, precipitation in Cat Ba Island decreased about 5.8\% (Figure 6). In addition, sea level in the island rose about $20 \mathrm{~cm}$ over 47 years, from 1972 to 2018 (Figure 7). The interactions among these factors will temporally affect the water availability in the island's drilled and dug wells, household rainwater tanks and reservoirs. These changes, coupled with high rates of population growth and tourism development have caused to high water shortages in the Cat Ba Island over last several summers, especially in the summers of 2017 and 2018 (CHWSP, 2019). The water shortages are expected to be more serious over coming decades, thereby probably constraining socio-economic development for the $\mathrm{Cat} \mathrm{Ba}$ Island.

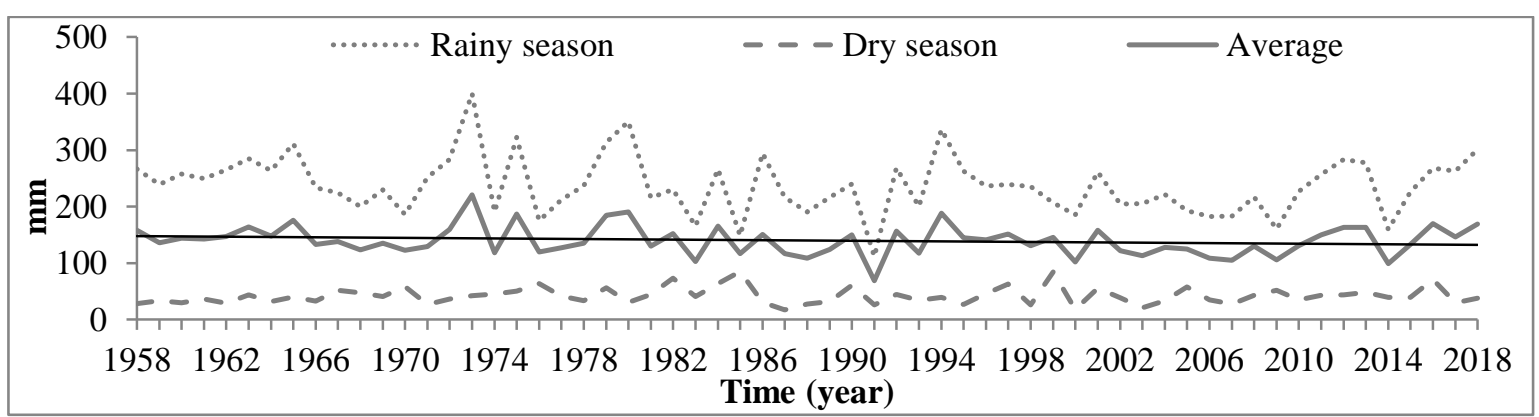

Figure 6. Precipitation in the Cat Ba Island over a 61 year period, from 1958 to 2018 (NNMWS, 2019) 


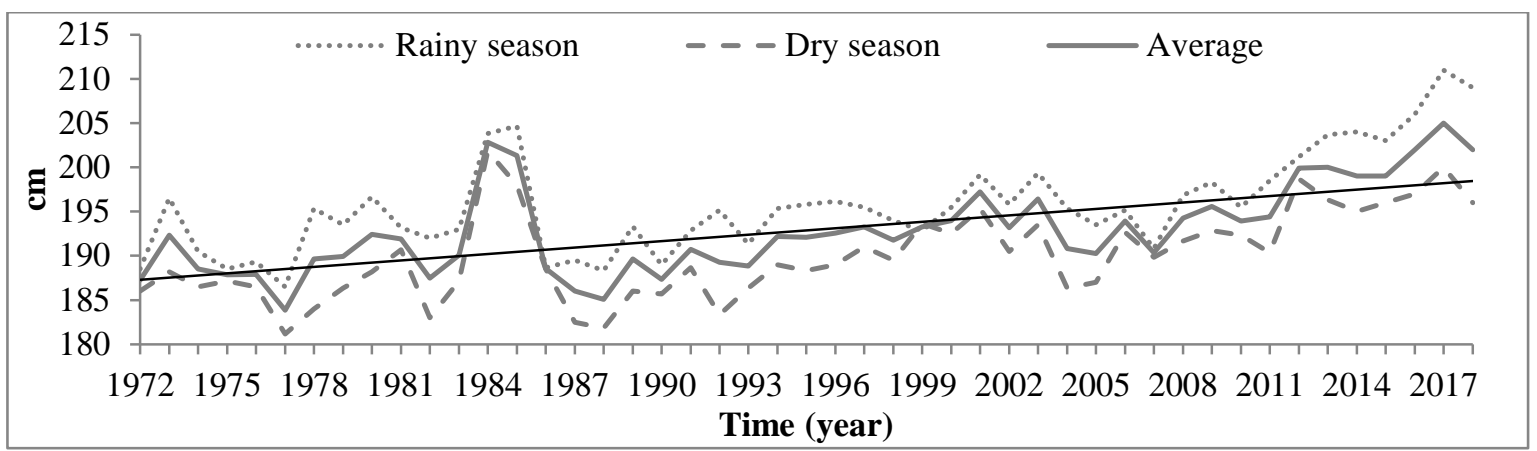

Figure 7. Sea level in the Cat Ba Island over a 47 year period, from 1972 to 2018 (NNMWS, 2019)

The change in water supply relative to water demand leads to changes in the water availability in the island through time. If water supply is less than water demand, resulting in a water deficit, actions will be required to secure future water for the Cat Ba Island by increasing water supply and/or reducing water consumption. Twelve adaptation options were identified from the interviewed results as potential options for increasing future water supply and reducing future water demand (Table 2). These twelve options were then carefully considered by focus group discussions on their effectiveness and feasibility and only six adaptation options were incorporated into the CLD to understand their interactions in increasing water supply and/or decreasing water demand in the Cat Ba Island's water system. These options act via six balancing loops in the CLD (B4 to B10).

The drilled wells will extract groundwater to supply water for the Cat Hai Water supply plant before supplying freshwater for domestic uses (e.g. households, hotels, and restaurants). However, if taking more groundwater from drilled wells, the groundwater level around drilled wells' areas will be decreased, thereby affecting the water exploitation from households' dug wells. Local people in the areas of operating drilled wells stated that their dug wells are increasingly dry because of exploiting groundwater from drilled wells in the areas. These relationships are represented via four balancing loops, B1, B2, B3 and B4. Hai Phong Department of Agricultural and Rural Development have a plan to build two more reservoirs to collect and store rainwater for dry seasons in the island. However, the construction of these two reservoirs has been halted due to insufficient budget (CHWSP, 2019). Recently, Hai Phong Water Supply Company has installed a desalination plant with a capacity of $1,500 \mathrm{~m}^{3} /$ day in the island in order to sufficiently supply water for a high water demand in the dry and tourism seasons. However, the cost for converting seawater to freshwater is very high and thus it will affect the water price in the Cat Ba Island. The interviewed results also suggested that it is necessary to build more household rainwater tanks to collect rainwater for uses in the dry seasons when water is not sufficiently supplied by the Cat Hai Water Plant. Using a large tube to transport water from mainland to supply water for the island was also suggested by local people. The interactions of these four adaptation options are depicted by four balancing loops (B5 to B8). In addition, increasing water price and using water efficient technologies were suggested by the respondents, aiming to decrease the water consumption from households and hotels and restaurants, represented by two balancing loops (B9 to B10).

Interactions between these ten balancing feedback loops seek the stability in water supply for efficiently secure water resources to meet a growing water demand from socio-economic development and seven of these ten balancing loops (B4 to B10) create a "drifting goals" system archetype (Maani \& Cavana, 2007). This archetype begins with standard goal seeking loops (B4 to B8) which attempt to increase water supply via actions for maintaining water availability. Delays typically arise between initial implementation of supply augmentation options and subsequent increases in water supply. In contrast, goal seeking loops (B9 and B10) which act to reduce water demand generally take less time to implement (Maani \& Cavana, 2007). It might therefore be important to consider differences in the time taken to achieve desired outcomes when selecting management interventions for maintaining or increasing water availability in the system.

\section{DISCUSSION AND CONCLUSION}

This paper aims to apply an integrated approach for improved management of scarce water resources in the Cat $\mathrm{Ba}$ Island, Vietnam under high levels of climate change and socio-economic development. Historical data collection, household interviews and focus group discussions were conducted to develop the CLD which presents the interactions and relationships amongst different climatic and non-climatic drivers on the island water system. These steps play an important role in determining a system structure which includes positive and negative relationships between variables, feedback loops and delays in the system. The historical data and the CLD indicated that water demand has been significantly increased over last decades due to high 
levels of population growth and tourism development in the Cat Ba Island. However, water supply from drilled and dug wells, household rainwater tanks and reservoirs is highly vulnerable to water shortages due to precipitation decline and sea level rise. The interactions among these factors have been causing high water shortages to the $\mathrm{Cat} \mathrm{Ba}$ Island over last several summers. The water shortages are expected to be more serious over coming decades, thereby probably constraining socio-economic development for the $\mathrm{Cat} \mathrm{Ba}$ Island. These are evidenced by two reinforcing loops (R1 and R2) in the water demand side and ten balancing loops (B1 to B10) in the water supply side.

In the next stage of this study will apply a system dynamics model (SDM) to assess the vulnerability of the island water system in 47 years, from 2014 to 2050 under climatic and non-climatic changes. The key climatic and non-climatic drivers and adaptation options from the CLD will be incorporated into the SDM to assess the vulnerability of the island water system and the effectiveness of adaptation options under climate change and socio-economic stressors over time. The SDM will be calibrated using historical data and validated by stakeholders in the Cat Ba Island. The study also will apply a contingent evaluation method to examine the determinant factors influencing respondents' willingness to pay (WTP) for building reservoirs and increasing water price for improved management of scarce water resources in highly developed tourism islands under climate change. The logistic regression models and Bayesian networks will be applied to quantify the relationships between respondents' WTP and respondents' socio-demographic characteristics (e.g. gender, age, education level, income, occupation) as well as respondents' perceptions on the management of scarce water resources (e.g. effects of climate change and socio-economic stressors on water resources). The results of this study will assist decision-makers and water managers to understand dynamics behaviour of the water system over time, and respondents' perceptions and willingness to support for the management of water resources, thereby adapting more effective practices for improved management of scarce water resources in the Cat Ba Island subject to high levels of climate change and tourism development.

\section{ACKNOWLEDGEMENT}

This study is supported by Australian Government through the Australian Alumni Grants Fund (Grant number: SGF - R2 - 00199). We are grateful to local stakeholders who significantly contributed to the CLD development and historical data collection, and local people who participated in the interviews.

\section{REFERENCES}

CHDS. (2019). Socio-economic data in Cat Ba Island, Hai Phong, Vietnam. Retrieved from Cat Hai Division of Statistics, Hai Phong, Vietnam:

CHWSP. (2019). Annual reports on water supply capacities for socio-economic development in Cat Ba Island. Retrieved from Cat Hai Water Supply Plant, Cat Hai, Hai Phong:

Halkos, G., \& Matsiori, S. (2016). Determining public attitudes and willingness-to-pay for artificial lakes protection. Water Resources and Economics, 15, 15-27. doi:10.1016/j.wre.2016.05.001

Maani, K. E., \& Cavana, R. Y. (2007). System Thinking, System Dynamics: Managing Change and Complexity. New Zealand: Pearson.

Mai, T., \& Smith, C. (2015). Addressing the threats to tourism sustainability using systems thinking: a case study of Cat Ba Island, Vietnam. Journal of Sustainable Tourism, 23(10), 1504-1528. doi:10.1080/09669582.2015.1045514

Nguyen, N. C., \& Bosch, O. J. H. (2013). A Systems Thinking Approach to identify Leverage Points for Sustainability: A Case Study in the Cat Ba Biosphere Reserve, Vietnam. Systems Research and Behavioral Science, 30(2), 104-115. doi:10.1002/sres.2145

NNMWS. (2019). Climate data in Hai Phong City, Vietnam. Retrieved from National Northeast Meteorological and Weather Stations, Hai Phong, Vietnam:

Phan, T. D., Nguyen, N. C., Bosch, O. J. H., Nguyen, T. V., Le, T. T., \& Tran, H. T. (2016). A Systemic Approach to Understand the Conservation Status and Viability of the Critically Endangered Cat Ba Langur. Systems Research and Behavioral Science, 33(6), 742-752. doi:10.1002/sres.2387

Richards, R., Sanó, M., Roiko, A., Carter, R. W., Bussey, M., Matthews, J., \& Smith, T. F. (2013). Bayesian belief modeling of climate change impacts for informing regional adaptation options. Environmental Modelling \& Software, 44, 113-121. doi:10.1016/j.envsoft.2012.07.008

Sterman, D. J. (2000). Business dynamics: Systems thinking and Modelling for a complex world. United States of America: The McGraw-Hill Companies. 